\title{
-Editorial-
}

\section{Biological agents - hope and caution}

\author{
Jaroslava Halper \\ Department of Pathology, College of Veterinary Medicine, The University of Georgia,Athens, GA 30602-7388
}

Corresponding Author: Jaroslava Halper, M.D., Ph.D., Department of Pathology, College of Veterinary Medicine, The University of Georgia, Athens, GA 30602-7388, USA. Tel: (706)542-5830, Fax: (706)542-5828, E-mail: jhalper@uga.edu

Received: $2011-12-15$

DOI : $10.5430 /$ jst.v1n3p155
Accepted: $2011-12-20$

URL: http://dx.doi.org/10.5430/jst.v1n3p155
Published: $2011-12-21$

Having actively participated in the field of growth factor research since the early days of growth factor discovery ${ }^{1,2}$ I can comment with great delight and amazement on the progress made since those early days. Not only our basic knowledge has expanded exponentially, but growth factors, their receptors and complicated signaling systems became legitimate targets of sometimes quite effective chemotherapy. This issue brings a variety of interesting papers dealing with various aspects of tumor therapy, ranging from traditional combination protocols for management of cholangiocarcinoma ${ }^{3}$ to novel hypofractionated stereotactic radiation therapy of pituitary adenomas ${ }^{4}$ to several papers which critically appraise the state of the art of cancer treatment with several recently introduced biological agents. ${ }^{5-8}$

Since the introduction of imatinib mesylate or Gleevec ${ }^{\circledR}$ as the first tyrosine kinase inhibitor and the first specific biological agent for treatment of malignant tumors (e.g. chronic myelogenous leukemia and gastrointestinal stromal tumors) in 2001, 10 many more biological drugs have been added to the oncology armamentarium, though not all of them have been as successful as Gleevec ${ }^{\circledR}$. The reason is that the picture is more complex than originally imagined. In many case the agent is less specific than anticipated, and therefore less effective against a given malignancy, and associated with sometimes unexpected side effects, ranging from minor effects like fatigue to major events, including death.

Bevacizumab (widely known under its trade name Avastin ${ }^{\circledR}$ ) is a monoclonal anti-VEGF antibody that has been used in combination with classic chemotherapeutic drugs to treat patients with metastatic carcinoma of the colon or rectum, and patients with unresectable, locally advanced, recurrent or metastatic non-squamous non-small cell lung cancer since $2004 .{ }^{9}$ Very recently the Food and Drug Administration has withdrawn its approval to use bevacizumab in patients with metastatic breast cancer for lack of effectiveness. ${ }^{11}$ As discussed by Ang and Kemeny ${ }^{6}$ the results have been somewhat varied even in patients with colorectal cancer. Though active as a first and second line agent, in combination with other chemotherapeutic drugs, such as 5-fluorouracil and oxaliplatin, bevacizumab can lead to unwanted side effects in other protocols. They report that some patients with KRAS wild-type metastatic colorectal cancer who have been treated with dual inhibition of epidermal growth factor receptor (EGF-R) (with cetuximab and panitumumab, antibodies against EGF-R) and VEGF (with bevacizumab) developed toxic effects and their survival was shorter. These unexpected toxic effects, such as pulmonary emboli and dermatological problems are likely due to crosstalk and overlap among the different signaling pathways activated by growth factors, their receptors and molecules such as hedgehog (see below). Because of the pathway activation the outcome is less specific and less potent (and sometimes even deleterious) in suppressing tumors than originally anticipated. In addition, bevacizumab should not be used as an adjuvant because its efficacy has not been shown in that setting. 
The authors also hypothesize that anti-angiogenic agents such as bevacizumab have direct modulatory effects on tumor cells as well as on the immune system. This connection between immune function and chemotherapy in patients with colorectal cancer is highlighted by Riss and Oehler. ${ }^{5}$ They comment that high density of infiltrating CD45R0+ cells in combination with CD8+ cells was associated with a good clinical prognosis, in contrast, early metastatic invasion correlated with decreased levels of CD8+ T cells. They propose to tailor chemotherapy to modify immune function in favor of the patient. For example, chemotherapy-induced apoptosis of tumor cells can trigger antitumor immune response. Such innovative approaches will require more research into modulation of immune responses and apoptosis by growth factors and cytokines, their signaling systems, and therapeutic antibodies developed against individual components of such systems.

In the context of colorectal carcinomas, it is worthwhile to read the report on the role of hedgehog gene (Hh) in pathogenesis of gastrointestinal cancers, such as carcinomas of the oesophagus and stomach, by Yang, et al. ${ }^{8}$ Hh signaling is activated in both types of carcinomas (just like in B-cell malignancies ${ }^{12}$ ), and has been found to be elevated in precancerous lesions as well. Several inhibitors of Hh signaling have been examined in animal studies and in cell cultures for their ability to suppress proliferation of these carcinoma cells. It appears that Hh pathway inhibitors, mostly SMO antagonists, showed synergistic effects with chemotherapeutic agents, radiation and inhibitors of pathways and molecular in cancer treatment. Again there is evidence of crosstalk between the Hh pathway and other signaling pathways at least in gastric cancer: activation of Hh signaling in gastric cancer by activated estrogen receptor-alpha pathway promotes gastric cancer cells proliferation. In contrast, Hh signaling inhibits the Wnt pathway. ${ }^{8}$ Studies coming from other groups confirm similar results with Hh inhibitors in colorectal carcinomas. ${ }^{13,14}$

Sorafenib is an inhibitor of VEGF and PDGF receptor, and the Ras-Raf kinase pathway. It has been found effective in patients with renal cell carcinoma, lung cancer, and hepatocellular carcinoma. ${ }^{15}$ Side effects associated with this type of therapy are the consequence of the biological activity of these agents and hypertension, thromboembolism and/or hemorrhage are some of the most dangerous effects of sorafenib. ${ }^{9}$ Galmiche et al. are sharing with us their experience with sofarenib in the treatment, or rather only in modest extension of life of patients with hepatocellur carcinoma. ${ }^{7}$

What are the lessons to be learned from these high hopes, trials, errors and trepidations associated with the use of biological agents? As Galmiche et al. suggest optimizing the control of the kinome of the cancer cell will identify kinases primarily involved in proliferation of cancer cells. ${ }^{7}$ Sine qua none of this premise is better understanding of the basics, in this case of the crosstalk within the kinome, or the set of protein kinases. ${ }^{7,16}$ This means that development of future biological drugs has to concentrate on components further down the various signaling pathways, and it will have to be two-pronged or even manifold - a combination therapy consisting of several agents, each directed against a different step or mediator in the signal transduction medley.

Acknowledgment: I would like to thank Dr. Helen Karsai for her critical reading of the manuscript.

\section{REFERENCES}

[1] Halper, J. and H.L. Moses. Purification and characterization of a novel transforming growth factor. Cancer Res 1987; 47: 4552-4559. PMid:2887280

[2] Parnell, P.G., et al. Transforming growth factor type-e: amino acid analysis and partial amino acid sequence. Growth Factors 1992;7:65-72. http://dx.doi.org/10.3109/08977199209023938 PMid:1503782

[3] Mohamed, A.W., et al. Hilar cholangiocarcinoma fifteen-year experience with 243 patients at a single Egyptian center. Journal of Solid Tumors 2011; 1 : 112-119. http://dx.doi.org/10.5430/jst.v1n3p112

[4] Bhatt, A.D., et al. Hypo-fractionated stereotactic radiotherapy for peri-optic pituitary adenomas - Early results of a novel experience. Journal of Solid Tumors 2011;1:103-111. http://dx.doi.org/10.5430/jst.v1n3p103

[5] Riss, S. and R. Oehler.Tumor infiltrating immune cells - potential powerful predictors in colorectal cancer patients. Journal of Solid Tumors 2011;1:8789. http://dx.doi.org/10.5430/jst.v1n3p87

[6] Ang, C., S.-P. and N.E. Kemeny.Bevacizumab in the management of colorectal cancer: A review. Journal of Solid Tumors 2011;1:120-131. http://dx.doi.org/10.5430/jst.v1n3p120

[7] Galmiche, A., et al. Sorafenib and the medical treatment of hepatocellular carcinoma. Journal of Solid Tumors 2011;1:132-136. http://dx.doi.org/10.5430/jst.v1n3p132

[8] Yang, L., J. Xie, and X. Su. Activation of the hedgehog pathway in gastroesophageal cancers. Journal of Solid Tumors 2011; 1:137-149. http://dx.doi.org/10.5430/jst.v1n3p137

[9] Halper, J. Growth factors as active participants in carcinogenesis: a perspective. Vet Pathol 2010;47: 77-97. http://dx.doi.org/10.1177/0300985809352981PMid:20080487

[10] B.J., D., et al. Efficacy and safety of a specific inhibitor of the BCR-ABL tyrosine kinase in chronic myeloid leukemia. New Engl J Med 2001;344: 1031-1037. http://dx.doi.org/10.1056/NEJM200104053441401 
[11] FDA commissioner removes breast cancer indication from Avastin label. 2011.

[12] Dierks, C., et al. Essential role of stromally induced hedgehog signaling in B-cell malignancies. Nat Med 2007;13: 944-951. http://dx.doi.org/10.1038/nm1614 PMid:17632527

[13] Mazumdar, T., et al. Blocking Hedgehog survival signaling at the level of the GLI genes induces DNA damage and extensive cell death in human colon carcinoma cells. Cancer Res 2011; 71: 5904-5914. http://dx.doi.org/10.1158/0008-5472.CAN-10-4173

[14] Wu, J.Y., et al. Cyclopamine blocked the growth of colorectal cancer SW116 cells by modulating some target genes of Gli1 in vitro. Hepatogastroenterology 2011;58:1511-1518. http://dx.doi.org/10.5754/hge10765

[15] Llovet, J.M., et al. Sorafenib in advanced hepatocellular carcinoma. N Engl J Med 2008;359:378-390. http://dx.doi.org/10.1056/NEJMoa0708857 PMid:18650514

[16] Manning, G., et al. The protein kinase complement of the human genome. Science 2002; 298: 1912-1934. http://dx.doi.org/10.1126/science.1075762 PMid:12471243 